\title{
Espaços específicos e pedagógicos para a educação de alunos surdos: recorrências nos discursos da ANPED no período de 1990 a 2010
}

Cinara Franco Rechico Barberena*

\section{Resumo}

Os diferentes espaços da escola em que os surdos são localizados sofrem (re)configuraçôes de nomeaçôes, de vieses de práticas pedagógicas que, apesar de delinearem deslocamentos de ênfases, continuam a localizar um espaço especial (ou específico) para trabalhar e discutir a surdez e os sujeitos surdos. O presente trabalho analisa como os discursos que circulam na ANPEd no período de 1990 a 2010 caracterizam os espaços escolares específicos e pedagógicos em que os alunos surdos estão inscritos. Invisto, então, em tensionar flashes da história da escola, bem como os saberes ali articulados, para problematizar a constituição dos surdos nesse e a partir desse cenário. O caminho teórico-metodológico recorre aos discursos produzidos na ANPEd no período de 1990 a 2010 que tematizam a escola e a inscrição da surdez e dos alunos surdos, sob a inspiração genealógica foucaultiana. $\mathrm{Na}$ análise, foi possível perceber que a escola, tanto especial quanto regular, é o grande espaço mencionado nos trabalhos para que a educação de surdos seja problematizada e é vista também como espaço de defesa da convivência surda e da língua de sinais. Contudo, as práticas, e nelas os saberes sobre os surdos, são inscritas com nuances modernas, embora a discussão sobre a diferença cultural alimentada nos trabalhos seja mobilizada por uma causa contemporânea.

Palavras-chave: Educação; Alunos surdos; Escola.

* Professora doutora da Universidade Federal de Roraima, Boa Vista, Roraima, Brasil. 


\section{Specific and pedagogical settings for deaf student education: recurrences in ANPED discourses from 1990 to 2010}

\section{Abstract}

The different settings in which the deaf have been situated have undergone (re)configurations of denominations and biases of pedagogical practices that, despite delineating focus displacements, still point out a special (or specific) setting to work with and discuss about deafness and deaf subjects. This paper analyzes how the discourses spread in ANPEd from 1990 to 2010 characterized specific and pedagogical school settings in which deaf students are inserted. It attempts to tension some flashes of the school history, as well as the knowledges it articulates, in order to problematize the constitution of the deaf in and from that scenario. From the Foucauldian genealogical perspective, the theoretical-methodological path taken comprehends discourses produced in ANPEd from 1990 to 2010 with a focus on the school and the insertion of deafness and deaf students. The analysis enabled the perception that both special and regular schools are the major settings mentioned in the papers for deaf education to be problematized and are also regarded as places to advocate both deaf living together and sign language. However, the practices and knowledges about the deaf are marked with modern nuances, although the discussion about cultural difference carried out in the papers is mobilized by a contemporary cause.

Keywords: Education; Deaf students; School.

\section{Introdução}

O presente trabalho é um recorte de uma pesquisa maior que tematiza as práticas pedagógicas que constituem alunos e sujeitos surdos na escola e na sociedade Contemporânea, a partir dos discursos que circulam na ANPEd. Para o momento, interessou-me analisar como os discursos que circulam na ANPEd no período de 1990 a 2010 caracterizam os espaços escolares específicos e pedagógicos em que os alunos surdos estão inscritos. Invisto, então, em tensionar flashes da história da escola, bem como os saberes ali articulados, para problematizar a constituiçáo dos surdos nesse e a partir desse cenário.

A recorrência discursiva dos espaços específicos e pedagógicos se torna relevante neste estudo devido a escola, tanto especial quanto regular, ser um dos grandes espaços mencionado nos trabalhos para que a educação de surdos seja problematizada. Também é o espaço para a defesa da convivência surda e da língua de sinais. Diria que a ANPEd serve de palco estratégico para a luta de muitos especialistas filiados ao movimento surdo para mostrar à academia e aos especialistas da Educação Especial a potência e a existência da surdez como marca de uma diferença culturalmente construída. Afirmar isso não implica o mesmo que dizer que toda leitura culturalmente construída sobre a surdez esteja dentro do espectro antropológico da diferença étnica, 
mas que toda leitura possível da materialidade surdez ou da materialidade pessoa com surdez é construída culturalmente e potencialmente, no caso dos surdos, dentre outros espaços, na escola. Por essa razão, pensar a escola como espaço de potência e de reunião de surdos torna-se fundamental.

Compreendo que a escola fez (e, em boa medida, continua fazendo) mais do que disciplinar os indivíduos submetidos a ela e mais do que ensinar determinados saberes a esses indivíduos. A escola funciona como a instituição Moderna mais poderosa, caracterizada por "uma íntima articulação entre o poder e o saber, de modo a fazer dos saberes a correia (ao mesmo tempo) transmissora e legitimadora dos poderes que estáo ativos nas sociedades modernas e que instituem e continuam instituindo o sujeito" (VEIGA-NETO, 2007, p. 114). Em face disso, ao longo da Modernidade, a escola, ao encarregar-se de criar o sujeito moderno, estabeleceu-se como uma grande maquinaria social e cultural. Diante disso é que tomo neste texto a escola como uma maquinaria para pensar a surdez e os alunos surdos. Para desmembrar a presente discussáo apresento primeiramente o caminho metodológico, para em seguida vislumbrar como a invenção de espaços específicos e pedagógicos para a educação de alunos surdos inscreve-se nesse embate possibilitando pensar (e continuar pensando) a escola e os sujeitos surdos.

\section{Caminho metodológico}

Para a presente investigação escolhi como caminho teórico-metodológico olhar para os discursos produzidos na ANPEd no período de 1990 a 2010 sob inspiração genealógica foucaultiana. Ao optar por esta inspiração para organizar tal pesquisa, quero dizer que busco pela possibilidade de leitura de enredamentos discursivos do presente. Dessa forma, buscando recorrências nos discursos que circulam na ANPEd, entendo que os embates teóricos ali travados emergem de relaçóes de poder, constituindo uma discursividade qualificada como verdadeira.

Nesta esteira entendo discurso como "conjuntos de signos (elementos significantes que remetem a conteúdos ou a representaçóes), como práticas que formam sistematicamente os objetos de que falam" (FOUCAULT, 2008, p. 55), para visualizar as diferentes maneiras pelas quais os discursos operam dentro de uma rede de poder, produzindo sentidos.

Para compreender as relaçóes que as verdades dos discursos produzem, sem entrar em juízo de valor, recorro à ANPEd e à forma como se constituiu como um evento, como um espaço entrelaçado com a Educação Especial onde circulam especialistas e um emaranhado de saberes que tecem a educação na Contemporaneidade. Justifico a escolha da ANPEd pela sua representação no meio acadêmico como um dos mais expressivos eventos na área de educação do nosso país; pela sua composição em Grupos de Trabalho, permitindo a liberdade de escolha do lugar em que se quer transitar academicamente; pelo reconhecimento acadêmico e discursivo dos especialistas da Educação Especial e da educação de surdos; pelo espaço que as pesquisas de pós-graduaçáo ocupam no evento, ao mesmo tempo em que transitam em diferentes terrenos teóricos e aproximam, por meio de seus dados e análises, a escola e as práticas pedagógicas com os alunos para serem pensadas. 
A educação de surdos a partir de seus materiais, anunciam que os saberes que a constituem partem do campo de saber da Educação Especial. Tal afirmação faz-se devido os dados quantitativos em que é representado, ou seja, há 54 trabalhos que tematizam a surdez e os alunos surdos inscritos no GT da Educação Especial e 3 trabalhos no GT dos Movimentos Sociais, Sujeitos e Processos Educativos. Sob esse patamar é que vislumbro possibilidades para pensar a invenção de espaços específicos e pedagógicos para a educação de alunos surdos.

\section{A invenção de espaços específicos e pedagógicos para a educação de alunos surdos}

As relaçóes desenhadas pela maquinaria escolar desdobram-se desde o pensamento de Comenius ${ }^{1}$, no século XVII, quando, para muitos historiadores da educação, começam a instituir-se as bases para o pensamento moderno da educaçáo. Entendendo-se o homem em sua "natureza educável" e que, para sua educação, é preciso sistematizar saberes, organizando-os dentro de uma hierarquia regida do mais simples ao mais complexo, pensa-se na invenção do método como um artefato que orienta a aprendizagem dos indivíduos para que todos atinjam os resultados esperados (NARODOWSKI, 2001). Desse modo, a escola Moderna constrói-se a partir de metas e ideais desejáveis para ajustar os homens ao funcionamento da sociedade, tornando-os, assim, sujeitos.

[...] a escola moderna se constituiu como uma imensa maquinaria cujos princípios proclamados apontaram cada vez mais para os ideais do Iluminismo; e, ao mesmo tempo, como uma imensa maquinaria cujas práticas estiveram sempre mais ou menos ajustadas ao funcionamento do mundo que estava sendo construído a partir desses ideais. (VEIGA-NETO, 2000, p. 192).

A escola Moderna, com sua funçáo ordenadora, regulamentadora, centrava-se no indivíduo com comportamento desviante, especialmente em relaçáo à pobreza, aos desvios, às deficiências, para intervir e manipular qualquer possibilidade de desestabilizaçáo da ordem social. Essa racionalidade constitui-se a partir do saber pedagógico sintonizado com diversos campos de saber, como o da medicina, o da psiquiatria e o da economia, dentre outros, com o intuito de instruir e regular condutas. A engrenagem escolar, nesse sentido, ocupa-se da "[...] necessidade de enquadramento das populaçôes em risco ou em perigo moral. Todo o trabalho de socialização escolar será, assim, apresentado como um trabalho de natureza disciplinar e disciplinadora" (Ó, 2003, p. 14).

Segundo Varela e Alvarez-Uria (1992), a instituição escolar configurava-se como um espaço civilizador das crianças que almejava regenerar tanto as de classes populares quanto as que não se adaptavam à escola disciplinar. Os indivíduos ou grupos que não se enquadravam no modelo almejado precisariam ser normalizados. Entendo, entâo, que técnicas e artefatos clínicos e pedagógicos eram postos em funcionamento para agir sobre o corpo do aluno surdo para que se assemelhasse o mais possível com a norma considerada desejável, no caso, a de ser ouvinte. Nessa premissa, as técnicas de oralização e as sessôes de treinamento auditivo, dentre outras, operam 
no corpo surdo como estratégias da escola Moderna para normalizá-lo. Tal concepção é notada nos trabalhos que circulam na ANPEd sobre a surdez e a escolarizaçáo dos alunos surdos, num recorte temporal do ano de 1994, em que a escola é descrita com espaços escolares e pedagógicos que conduzem os alunos surdos a certos modos de vida, conforme excerto a seguir:

É uma escola de grande área física, contando com algumas salas de aula e cabines equipadas com aparelhagem de amplificação sonora. Tem pátios de recreação, campo de futebol, ginásio esportivo, refeitório, centro de diagnóstico e adaptaçáo de prótese, salas para reuniōes, auditório e oficinas pedagógicas além, das instalaçôes próprias para a administração. (MN, 1994c, p. 105).

Ao descrever uma escola e sua área física, a inscrição de cabines equipadas com aparelhagem de amplificação sonora e o centro de diagnósticos e adaptação de prótese não só compreende possibilidades pedagógicas que a escola oferece, mas a função desses espaços na formação dos alunos que ali transitam. É possível visualizar que os alunos surdos de escolas como essas são conduzidos a assumir essas atividades pedagógicas e/ou clínicas como fundamentais para a sua formação. Desse modo, as condutas estáo sob um exercício de poder que permite o controle da anormalidade e práticas de reabilitaçáo e cura.

Com o objetivo de ajustar os homens ao funcionamento da sociedade, de corrigir as diferentes aptidóes, a educação passa a ser o ponto de partida, reforçando o papel de normalização que a escola moderna se propóe a desempenhar. Desde Comenius, o ideal de escola para todos disseminado na Didática Magna já era sinalizado e estava associado à capacidade de educabilidade humana, abarcando a todos. Ao referir-se a todos, o filósofo estava se referindo a homens, mulheres e pobres. Assim, o pensamento comeniano de "ensinar tudo a todos" é inscrito também na escola contemporânea sob os parâmetros de normalizar, de moldar os sujeitos a partir de um discurso binário que localiza certo e errado, normal e anormal, bom e mau, o que aprende e o que não aprende, dentre outras classificações possíveis. Nessa concepção, o próprio autor marca o anormal como exceção, e, dessa forma, a educabilidade humana institui-se como ponto de partida para a educação e define o padrão da normalidade do homem. Dito de outro modo, o alvo da escola é a produção dos normais, tendo em vista que nasceram aptos para aprender.

Dessa forma, o campo de saber da Educação Especial instituiu-se como uma racionalidade científica preocupada e encarregada de lidar com os alunos que não se enquadram na norma, "os ineptos"), os deficientes e, então, os surdos. Nesse sentido, é possível visualizar esse campo de saber emergindo nos discursos que circulam na ANPEd, como no recorte extraído do ano de 1992:

A educação especial pode ser definida como uma modalidade de educação formal, que não se diferencie do ensino regular, na sua essência, ou seja, nos seus objetivos, nas suas finalidades, os seus conteúdos, mas sim nos recursos metodológicos que precisam ser acrescidos, para que as diferenças das crianças sejam adequadamente trabalhadas, sem no entanto, transformá-las em desiguais. (AS, 1992, p. 1). 
A Educação Especial é marcada no cenário educacional como uma modalidade escolar que, numa relação com o ensino, no caso, o ensino regular, se diferencia nas estratégias pedagógicas, ou seja, em como possibilitar o conhecimento dos conteúdos e o desenvolvimento dos alunos na tentativa de apagar a desigualdade entre eles. Entendo que a centralidade discursiva que envolve tal discussão destaca os esforços da escola para trabalhar com as diferenças das crianças rumo ao apagamento da desigualdade. Trata-se de uma educação em que, para se estar em pé de igualdade, é relevante um ambiente pedagógico que dê condiçôes para que as crianças adquiram conhecimentos. Por vezes, essa relação escolar e social se fortalece ao partir da concepção de que "a pior forma de exclusão ${ }^{3}$ é deixar a criança sair da escola sem ter adquirido nenhuma aprendizagem, nenhum conhecimento, sem as ferramentas mínimas para se integrar e participar ativamente das sociedades [...]" (NÓVOA, 2007, p. 12).

A articulação da escola, do ensino e das práticas pedagógicas na busca da construção do conhecimento dos alunos é uma recorrência visível nos trabalhos que circulam na ANPEd nas décadas de 1990 e de 2000. Destaco os excertos a seguir:

É a escola que precisa se integrar ao surdo, recebendo-o nos termos que a natureza especial dele impóe. À escola compete ensinar conteúdos, dotar a criança surda do cabedal de conceitos, capacidades, conhecimentos, enfim, que lhe permitam compreender o mundo e nele agir e viver com as mesmas possibilidades que se descortinam para os indivíduos ouvintes. Aí, então, acredita-se que o surdo poderá vir a ser um cidadáo integrado à comunidade ouvinte. (MN; ER; MH; AS; JM; WM, 1996a, p. 8-9).

Dado que a linguagem constitui um processo determinante para o desenvolvimento da cogniçáo e da consciência, o sujeito surdo com certeza terá sérias dificuldades em significar o mundo e construir conhecimentos, visto que os contextos sociais onde comumente estáo inseridos, família e escola, usam uma língua falada. Este fato faz com que os surdos, em grande maioria, se sintam como interlocutores estrangeiros em seu próprio país (LACERDA, 1996; GÓES E SOUZA, 1997; GESUELI, 1998).A falta de domínio de uma língua comum entre surdos e ouvintes com certeza dificulta ou mesmo impede a interação, a comunicação e a própria construção de conhecimentos. (DT, 2002a, p. 2).

$\mathrm{Na}$ escola, as representaçóes da surdez como falta e como incapacidade se acentuam muitas vezes em razão de um universo linguístico e culturalmente adverso às necessidades das pessoas surdas, como, por exemplo, turmas de ouvintes com um aluno surdo, o qual tenta entender uma língua que não domina e à qual nem ao menos tem acesso. [...] Os alunos surdos permanecem desprovidos de língua, alijados de cultura, com currículos inadequados, náo compreendidos em suas singularidades, muitas vezes relegados à sua própria sorte no processo de construçáo do conhecimento. (TL, 2010b, p. 6).

A partir dessas recorrências, percebe-se que à escola compete ensinar conteúdos, conhecimentos, para os alunos como condição de acessibilidade e integração no mundo social. No caso dos alunos surdos, é fortemente firmado que essa condição de 
acesso ao mundo social está atrelada à ideia de conhecimento linguístico. A partir da década de 2000, em que se fortalecem as discussóes pautadas na educação bilíngue e, dessa forma, a incursão da língua de sinais na vida das pessoas surdas, os trabalhos evidenciam esse movimento discursivo. No início da década de 2000, é notório que a falta de domínio de uma língua comum entre surdos e ouvintes possibilita pensar em certas amarras do surdo e da questão linguística que o enreda como condição para seu desenvolvimento e aprendizagem. Num tempo em que a língua falada, ou seja, a língua portuguesa dominava os espaços pedagógicos em que os surdos estavam inseridos e em que se enalteciam as dificuldades do domínio dessa língua pelos alunos surdos, a construção de conhecimento desses educandos também se mostrava fragilizada.

Entretanto, à medida que as discussóes linguísticas envolvendo alunos e sujeitos surdos foram se compondo no cenário escolar e social, é possível visualizar deslocamentos produzindo outros rumos e outras balizas discursivas. Desse modo, a língua de sinais emerge como um fator favorável e propício para o desenvolvimento e a aprendizagem do aluno surdo. Porém, nesse sentido, ao partir do domínio linguístico da língua de sinais como pedágio para a acessibilidade na escola e na sociedade, outros elementos interpelam tal discursividade, fragilizando-a.

Com isso, a prática do domínio da língua de sinais incide tanto no aluno surdo quanto no professor e/ou nos profissionais envolvidos nessa relação. Os trabalhos da ANPEd evidenciam tal emergência ao pontuarem que, sem uma base sólida para a comunicação, não há como o professor mediar a elaboração de conhecimentos e que os alunos surdos permanecem desprovidos de língua, muitas vezes relegados à sua própria sorte no processo do conhecimento.

Sob as lentes arqueológicas, para o conhecimento, "o sujeito é um sujeito cognoscitivo ou cognoscente - enfim, um sujeito que conhece como resultado da sua açâo frente a um objeto cognoscível" (VEIGA-NETO; NOGUEIRA, 2009, p. 7). Os conhecimentos são dispostos de determinadas maneiras e com certas ênfases, de modo a criar as condiçóes de possibilidade para que todos entrem na rede das práticas em que estamos mergulhados.

Ao partir dessa discursividade que compóe os textos produzidos na ANPEd, vejo discussóes abarcando o conhecimento produzido pela/na escola sob a presença da questão linguística como pedágio de inserção do surdo na escola e na sociedade Contemporânea. Envolvida nessa teia discursiva e de análise, pergunto-me pelos feixes que compóem a produção do conhecimento, além do imperativo pedagógico linguístico. Dito de outro modo, invisto em olhar em que sentidos os conteúdos curriculares são postos nessa teia como preocupaçóes dos especialistas da área da surdez para pensar o desenvolvimento e a aprendizagem do aluno e do sujeito surdo.

Penso que a ênfase linguística foi reinscrita no funcionamento da maquinaria escolar e na condução de vida dos surdos, "uma vez que as políticas educativas e pedagógicas presentes nesse espaço abordam a questão da diferença sob o olhar da normalidade, reduzindo a diferença à diversidade ou então à deficiência" (ACORSI, 2009, p. 174). Compreendo a escola como uma rede que se movimenta e que se deixa 
movimentar; a partir de processos da norma e de normalização implícitos nesse contexto, buscam-se a homogeneização e o governamento dos sujeitos. A norma captura todos, produz saberes sobre os sujeitos com a finalidade "de torná-los passíveis da ação governamental, ou seja, de constituí-los como uma população governável” (LOPES et al., 2010, p. 12-13). Quando se toma a maquinaria escolar a partir da lógica Contemporânea, entende-se que a norma é construída no interior dos grupos sociais e que se mantém na escola de hoje, pois ela é o foco, o centro da escola. No entanto, diferentemente da sociedade disciplinar, não se parte mais da norma para nomear e fabricar os incapazes, os anormais, mas sim das recorrências, e é a partir deles que se estipula a norma. Dessa maneira, temos a multiplicação das normas e, diante disso, a exaltação da diferença e a proliferação dos grupos sociais e das formas de vida.

No que tange aos surdos, passa a existir uma norma surda vigente. A partir dela, define-se quem é o normal e o (a)normal surdo, ou seja, com base em uma grade de leitura de normalidade surda é que se desenha a comunidade, se define o padrão estabelecido.

Tal tensionamento decorre de que, os surdos como grupo social, como comunidade, se alastram discursiva, cultural e politicamente, assumindo posiçóes a partir da diferença surda, da cultura surda, colocando-se como normais e definindo a norma. Discursos e práticas pedagógicas projetam os surdos em elementos da diferença e de outros artefatos que os constituem na Contemporaneidade, mas percebo que são atravessados por uma busca de fixar um lugar de (a)normalização.

Posso pensar que a (a)normalidade surda é lida na Modernidade como um corpo que precisa ser normalizado, reabilitado em relação a um determinado padrão desejado. $\mathrm{Na}$ Contemporaneidade, o surdo insere-se social e politicamente, criando sua própria norma. Embora a noção de norma se inscreva num processo de atualizaçáo para pensar o sujeito surdo produzido na sociedade disciplinar e o sujeito surdo na sociedade de controle, parece-me que ambas almejam intervir com o propósito de capturá-lo para mais perto da zona de normalidade. É a partir dessa zona de normalidade que se constituirão as práticas pedagógicas e escolares da escola para trazer os sujeitos surdos para o normal. Nesse contexto, a inclusão emerge como uma possibilidade interessante para viabilizar o funcionamento da escola.

Desse modo, entendo que a escola na Contemporaneidade encontra-se sob a égide do pensamento de uma educação para todos e se reinscreve em diferentes espaços específicos e pedagógicos de educação. Os alunos surdos, os denominados na escola Contemporânea, dentre outras formas, como "alunos incluídos", são alvos de uma tentativa permanente de apagamento das diferenças em nome da igualdade e da inclusão.

Traço a seguir alguns arranjos discursivos a partir de recorrências extraídas dos trabalhos que circulam na ANPEd desde a década de 1990 até a década de 2000. 
[...] devemos ter clareza do caráter temporário que se deve imprimir à permanência do aluno nos serviços especializados, o que significa que tais modalidades - Escola Especial, Classe Especial, Sala de Recursos, Ensino Itinerante, Classe Comum - precisam se reorganizar, de forma a ajudar o aluno a superar as suas dificuldades e a prepará-lo para a integração no Ensino Regular, dispensando gradativamente, o suporte da Educação Especial. (AS, 1992a, p. 2-3).

Hoje, com o movimento de inclusão, é cada vez maior a necessidade de se criar um espaço, junto às escolas, para os seus profissionais se atualizarem em LIBRAS ou conhecerem a língua capaz de aproximá-los e de auxiliá-los a compreender os alunos surdos incluídos e instrumentalizá-los para ensinar. Além disso, considerando a nova política educacional, esse trabalho deve vir integrado com um atendimento de apoio à família, visando garantir o desenvolvimento educacional adequado aos alunos surdos. (TD; JR; CP; SC, 2001e, p. 4).

O movimento de inclusão vem acentuando uma tendência, que é de reorganizar os serviços de educação especial. Por consequência os professores que neles atuam sáo incorporados ao ensino regular ou passam a compor setores de apoio à inclusáo localizados fora das escolas e dentro das Secretarias de Educação. [...] (DT, 2006d, p. 7).

A criação de classes de surdos/as em escolas inclusivas com um número expressivo de alunos/as surdos/as, que possibilite a presença e a participaçáo significativa da comunidade surda, utilize uma abordagem educacional bilíngue bicultural e favoreça o desenvolvimento das potencialidades e a constituição das identidades dos/ as alunos/as surdos/as em condições semelhantes às oferecidas aos/ às alunos/as ouvintes, poderia amenizar os efeitos negativos da inclusão de surdos/as em classes de ouvintes e possibilitar a reduçáo dos elevados índices de exclusão e de discriminaçáo social e cultural desse grupo. (TL, 2007c, p. 14).

Com tais recorrências discursivas, evidencia-se a (re)configuração da escola na perspectiva inclusiva. Desde 1992, preceitos em torno dos espaços específicos de Escola Especial, Sala de Recursos, Classe Especial, Ensino Itinerante e Classe Comum deslizam no cenário da educação de surdos como possibilidades educacionais que permitem a esse alunado sua integração no ensino regular. De acordo com os trabalhos revisitados, esse tempo é marcado binariamente pela constituição da Escola Especial e/ou a Escola Integrada, até emergir, em torno do ano de 2000, a ideia de escola inclusiva associada intimamente com orientaçôes das políticas públicas e educacionais. Nesse sentido, percebe-se um significativo acento do movimento inclusivo (des)territorializando a Educação Especial em diferentes espaços específicos e pedagógicos - espaços como as salas de surdos, as classes de surdos, os espaços para ensinar e instrumentalizar a língua de sinais com as famílias e a inserção dos surdos no ensino superior.

As recorrências discursivas dos trabalhos da ANPEd permitem tomar os surdos como sujeitos que estão emaranhados num processo de (a)normalização. Digo 
isso tendo em vista que as práticas pedagógicas em que os alunos surdos estão enredados descrevem a necessidade de apoio específico pedagógico, de forma permanente ou temporária, para que alcancem seus objetivos na educação. Ou seja, estratégias são postas em funcionamento para que consigam acompanhar a aula e o processo educacional como o modelo desejado - o de ouvinte -, numa prática que os (a)normaliza e naturaliza sua circulação no meio social.

O disciplinamento, a correção, a normalização dos sujeitos marcadamente diferentes que cada vez ocupam espaços maiores na escola, passam a dar o tom das práticas pedagógicas nela engendradas, tendo em vista que é na escolarização que se tem a possibilidade de civilizaçáo dos sujeitos. A inclusáo de todos na escola permite uma população civilizada, um relevante expoente para garantir o governamento dos sujeitos.

A marcação das posições que os sujeitos ocupam na escola e também fora dela faz com que se coloquem e sejam colocados uns em relação aos outros, definindo que "uns são o que outros não são" (FABRIS; LOPES, 2003, p. 2). A diferença, tomada como ambivalência, como algo que perturba a ordem, precisa ser evitada, uma vez que se torna uma ameaça. Ao mesmo tempo em que a diferença passa a ser nomeada para que possa ser corrigida ou evitada, punida ou apagada, ela é também classificada e aparece como mais um ponto delineado pelas estatísticas, que acabam contribuindo para materializar o sucesso da educaçáo inclusiva na escola contemporânea.

\section{Considerações para continuar pensando:}

Ao término deste estudo, dentre tantas possibilidades de análise, percebi que as práticas, e nelas os saberes sobre os surdos, são inscritas com nuances modernas, embora a discussáo sobre a diferença cultural alimentada nos trabalhos extraídos da ANPEd seja mobilizada por uma causa contemporânea. Entendo neste contexto, que a circulação de saberes são colocados a partir de um conjunto de técnicas e práticas pedagógicas que não só descrevem o surdo sobre seus comportamentos, corpos e desenvolvimento, como também os inventam, pois tanto estar sujeito a saberes que descrevem e inventam, quanto estar sujeito a si mesmo pela dependência do saber do outro, são condiçóes para se viver na Modernidade.

No entanto, ressalto que novas formas de assujeitamento e subjetivação no mundo atual podem ser potencializadas por relaçóes de poder, o que é próprio de uma sociedade que se desloca da ênfase na disciplina, que produz sujeito obediente, fácil de conduzir porque aprendeu e assumiu certas disposiçóes mentais-corporais, submetendo-se a elas por si mesmo - para a ênfase no controle, que estimula a flexibilidade.

Portanto, nesta discussão a escola constitui-se como uma maquinaria que, ao agir por meio da vigilância, encontra-se intrinsecamente relacionada aos jogos de poder postos em funcionamento para produzir posturas, comportamentos e sujeitos. Nesse embate, visualizo que elementos de diferentes ordens, como discursos, instituiçóes, teorias, regulamentos e leis, práticas sociais, dentre outros, mantêm-se conectados numa rede de relaçóes cuja função é manter o poder de uns sobre os outros, a 
ação de uns sobre as açóes dos outros. Assim, a escola, na medida em que se encarrega das tarefas de ensinar, educar, vigiar e regular os alunos, institucionaliza-se e constitui-se como um lócus produtivo para pensar a invenção dos saberes pedagógicos e dos conceitos sobre a surdez e os alunos surdos.

\section{Referências}

ACORSI. R. Tenho 25 alunos e 5 inclusóes. In: LOPES, M.; HATTGE, M. (Orgs.). Inclusáo Escolar: conjunto de práticas que governam. Belo Horizonte: Autêntica, 2009.

FOUCAUlT, M. Segurança, Território e Populaçáo. Curso dado no Collège de France (1977-1878). São Paulo: Martins Fontes, 2008.

FABRIS, E. H.; LOPES, M. C. Quando estar junto transforma-se em uma estratégia perversa de exclusáo. 2003. Disponível em: <www.rizoma.ufsc.br/semint/ oficina\% 2003.htm>. Acesso em: 12 jun. 2012.

LOPES, M. C., et al. Inclusão e Biopolítica. Cadernos IHU, São Leopoldo: Unisinos, ano 8, n. 144, p. 3-30, 2010.

NARODOWSKI, M. Comenius e a Educação. Coleção Pensadores e Educação. Belo Horizonte: Autêntica, 2001.

NÓVOA, A. Nada substitui o bom professor. In: Desafios do trabalho do professor no mundo contemporâneo. Sinpro SP, jan. 2007.

Ó, J. R. do. O governamento de si mesmo. Modernidade pedagógica e encenaçóes disciplinares no aluno Liceal (último quartel do século XIX - meados do século XX). Lisboa: UI\&DCE, 2003.

VARELA, J.; ALVAREZ-URIA, F. A maquinaria escolar. In: SILVA, T. T. (Org.). O que produz e o que reproduz em educação. Teoria \& Educaçáo. Dossiê: história da educação. Porto Alegre: Artmed, 1992.

VEIGA-NETO, A. Espaços, tempos e disciplinas: as crianças ainda devem ir à escola? In: MAZZOTI-ALVES, A., et al. Linguagens, espaços e tempos no ensinar e aprender. Encontro Nacional de Didática e Prática de Ensino (ENDIPE). Rio de Janeiro: DP\&A, 2000.

Foucault \& a Educaçáo. 2. ed. Belo Horizonte: Autêntica, 2007.

VEIGA-NETO, A.; NOGUERA, C. E. Conhecimento e saber: alguns apontamentos. Texto elaborado como subsídio ao Programa Currículo em Movimento, sob a coordenação da Diretoria de Concepçôes e Orientaçôes Curriculares para Educação Básica do Ministério da Educação (DCOCEB/SEB/MEC). Março, 2009. Versão impressa.

\section{Notas}

${ }^{1}$ Com Narodowski (2001, p. 16), entendo que "a pedagogia comeniana implanta uma série de dispositivos discursivos sem os quais é praticamente impossível compreender a maior parte das posiçōes pedagógicas atuais [...] dispōe elementos sem os quais a Pedagogia moderna seria irreconhecível em suas principais facçóes e matizes presentes".

${ }^{2}$ Conceito utilizado por Comenius para designar as pessoas com diferentes aptidôes, vistas como defeitos da natureza (NARODOWSKY, 2001).

${ }^{3}$ Compreendo exclusão não de uma forma binária em relação com a inclusão; tomo esses dois conceitos como faces da mesma moeda, como invençôes deste mundo, invençóes datadas dos séculos XVI e XVII. Diferentes são os usos associados a essas palavras. Elas podem ser associadas à miséria vivida de um número grande de pessoas no território brasileiro; podem estar associadas à marcaçâo de limites entre o dentro e o fora, assim como podem estar associadas às situaçôes de discriminação negativa por razóes de raça/etnia, gênero, religiáo, deficiência, educaçáo, etc. (LOPES, et al., 2010). 
Cinara Franco Rechico Barberena

\section{Correspondência}

Cinara Franco Rechico Barberena - Universidade Federal de Roraima, Conselho Superior. Campus Paricarana - Av Cap. Enê Garcez, n. 2413, Aeroporto, CEP: 69304000 - Boa Vista, Roraima - Brasil.

E-mail: cinararechico@yahoo.com.br

Recebido em 15 de maio de 2015

Aprovado em 05 de agosto de 2015 